\title{
Buoyancy-induced convection from a pair of heated and cooled horizontal circular cylinders inside an adiabatic tilted cavity filled with alumina/water nanofluids
}

\author{
Massimo Corcione, Emanuele Habib, Alessandro Quintino, \\ Elisa Ricci and Vincenzo Andrea Spena \\ Department of Astronautical, Electrical and Energy Engineering, Sapienza \\ Università di Roma, Rome, Italy
}

Buoyancyinduced convection

Received 8 January 2019 Revised 15 February 2019 Accepted 5 March 2019

\begin{abstract}
Purpose - This paper aims to investigate numerically buoyancy-induced convection from a pair of differentially heated horizontal circular cylinders set side by side in a nanofluid-filled adiabatic square enclosure, inclined with respect to gravity so that the heated cylinder is located below the cooled one, using a two-phase model based on the double-diffusive approach assuming that the Brownian diffusion and thermophoresis are the only slip mechanisms by which the solid phase can develop a significant relative velocity with respect to the liquid phase.

Design/methodology/approach - The system of the governing equations of continuity, momentum and energy for the nanofluid, and continuity for the nanoparticles, is solved by a computational code based on the SIMPLE-C algorithm. Numerical simulations are performed for $\mathrm{Al}_{2} \mathrm{O}_{3}+\mathrm{H}_{2} \mathrm{O}$ nanofluids using the average volume fraction of the suspended solid phase, the tilting angle of the enclosure, the nanoparticle size, the average nanofluid temperature and the inter-cylinder spacing, as independent variables.

Findings - The main results obtained may be summarized as follows: at high temperatures, the nanofluid heat transfer performance relative to that of the pure base liquid increases with increasing the average volume fraction of the suspended solid phase, whereas at low temperatures it has a peak at an optimal particle loading; the relative heat transfer performance of the nanofluid has a peak at an optimal tilting angle of the enclosure; the relative heat transfer performance of the nanofluid increases notably as the average temperature is increased, and just moderately as inter-cylinder spacing is increased and the nanoparticle size is decreased.

Originality/value - The two-phase computational code used in the present study incorporates three empirical correlations for the evaluation of the effective thermal conductivity, the effective dynamic viscosity and the coefficient of thermophoretic diffusion, all based on a high number of literature experimental data.
\end{abstract}

Keywords Inclined enclosure, Natural convection of nanofluids, Optimal particle loading, Optimal tilting angle, Two-phase modeling, Differentially heated horizontal circular cylinders

Paper type Research paper

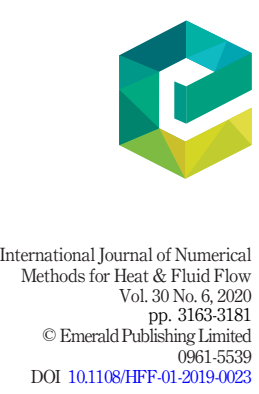

\author{
Nomenclature \\ c = specific heat at constant pressure, $\mathrm{J} /(\mathrm{kg} \mathrm{K})$; \\ $\mathrm{D}_{\mathrm{B}}=$ Brownian diffusion coefficient, $\mathrm{m}^{2} / \mathrm{s}$; \\ $\mathrm{D}_{\mathrm{T}}=$ thermophoretic diffusion coefficient, $\mathrm{m}^{2} / \mathrm{s}$; \\ $\mathrm{d}_{\mathrm{f}}=$ equivalent diameter of a base fluid molecule, $\mathrm{m}$; \\ $\mathrm{d}_{\mathrm{p}}=$ nanoparticle diameter, $\mathrm{m}$; \\ g = gravity vector, $\mathrm{m} / \mathrm{s}^{2}$;
}


HFF
30,6

I = unit tensor;

$\mathrm{J}_{\mathrm{p}}=$ nanoparticle diffusion mass flux, $\mathrm{kg} /\left(\mathrm{m}^{2} \mathrm{~s}\right) ;$

$\mathrm{k}$ = thermal conductivity, $\mathrm{W} /(\mathrm{m} \mathrm{K})$;

$\mathrm{k}_{\mathrm{b}}=$ Boltzmann constant, $1.38066 \mathrm{~s}^{2} 10^{-23} \mathrm{~J} / \mathrm{K}$;

$\mathrm{L} \quad=$ inter-cylinder spacing, $\mathrm{m}$;

$\mathrm{M}$ = molecular weight of the base fluid, $\mathrm{g} / \mathrm{mol}$;

$\mathrm{m}$ = nanoparticle mass fraction;

$\mathrm{N}=$ Avogadro number, $6.022 \mathrm{~s}^{2} 10^{23} \mathrm{~mol}^{-1} ;$

$\mathrm{Nu}=$ Nusselt number;

$\mathrm{p}=$ pressure, $\mathrm{Pa}$;

$\mathrm{Q}=$ heat transfer rate, $\mathrm{W}$;

$\mathrm{R}=$ cylinder radius, $\mathrm{m}$;

$\mathrm{Ra}=$ Rayleigh number;

$\mathrm{Re}_{\mathrm{p}}=$ nanoparticle Reynolds number;

$\mathrm{S}_{\mathrm{T}}=$ thermophoresis parameter;

$\mathrm{T}=$ temperature, $\mathrm{K}$;

$\mathrm{t}=$ time, $\mathrm{s}$;

$\mathrm{U}=\mathrm{x}$-wise velocity component, $\mathrm{m} / \mathrm{s}$;

$\mathrm{u}_{\mathrm{p}}=$ nanoparticle Brownian velocity, $\mathrm{m} / \mathrm{s}$;

$\mathrm{V}=$ velocity vector, $\mathrm{m} / \mathrm{s}$;

$\mathrm{V}=\mathrm{y}$-wise velocity component, $\mathrm{m} / \mathrm{s}$;

$\mathrm{x}, \mathrm{y}=$ Cartesian coordinates, $\mathrm{m}$; and

$\mathrm{W}$ = width of the cavity, $\mathrm{m}$.

\title{
Greek symbols
}

$\varphi=$ nanoparticle volume fraction;

$\lambda=$ dimensionless center-to-center separation distance between the cylinders;

$\gamma=$ tilting angle, deg;

$\mu=$ dynamic viscosity, $\mathrm{kg} /(\mathrm{m} \mathrm{s})$;

$\rho=$ mass density, $\mathrm{kg} / \mathrm{m}^{3} ;$ and

$\tau=$ stress tensor, $\mathrm{kg} /\left(\mathrm{m} \mathrm{s}^{2}\right)$.

\author{
Subscripts \\ av = average; \\ c = cooled cylinder; \\ $\mathrm{f}=$ base fluid; \\ $\mathrm{fr}=$ freezing point of the base fluid; \\ $\mathrm{h}$ = heated cylinder; \\ $\mathrm{n}$ = nanofluid; \\ opt $=$ optimal; and \\ $\mathrm{s}=$ solid phase.
}

\section{Introduction}

Buoyancy-induced convection of nanofluids inside adiabatic enclosures containing heated and cooled cylinders has recently gained a lot of interest, owing to its relevance to a number of potential thermal engineering applications. This is, for example, what happens in the indirect heat exchangers consisting of hot and cold pipes enclosed in an adiabatic case, whose thermal interaction is ensured by a third fluid contained within the case. 
The studies easily available in the literature on this topic were carried out numerically for a wide variety of configurations by Garoosi et al. (2013, 2015a, 2015b, 2016a, 2016b), Garoosi and Hoseininejad (2016), Garoosi and Talebi (2017a, 2017b), and by Khalili et al. (2017), yet some points have to be raised regarding these works.

In fact, half of the studies executed by Garoosi et al. (2013, 2016a, 2016b), Garoosi and Hoseininejad (2016) are based on the single-phase modeling, in which the nanofluid is treated as a pure fluid assuming that the solid and liquid phases are in local thermal and hydrodynamic equilibrium, thus meaning that the effects of the slip motion occurring between the suspended nanoparticles and the base liquid are completely neglected. On the other hand, in the remaining mentioned studies, all based on the two-phase approach, the thermophoretic velocity of the suspended nanoparticles is calculated by the way of the empirical relationship developed by McNab and Meisen (1973), whose applicability to nanofluids has never been demonstrated. Actually, such a relationship represents the best fit of experimental data relative to either water or $n$-hexane containing polystyrene latex particles with diameters of $0.790 \mu \mathrm{m}$ and $1.011 \mu \mathrm{m}$, i.e. from one to two orders of magnitude higher than the typical sizes of nanoparticles. In addition, the volume fraction of the suspended latex particles was estimated to be nearly 0.001 per cent, i.e. at least two orders of magnitude lower than the volume fractions typical of nanofluids. Finally, the ratio between the thermal conductivities of the solid particles and the base liquid was approximately $0.2-1$, i.e. one or two orders of magnitude lower than the values usual for nanofluids with suspended metal or metal-oxide nanoparticles. Accordingly, it cannot be said that the thermophoretic diffusion coefficient calculated by means of the McNab-Meisen relation is safely applicable to the currently used nanofluids. Indeed, thermophoretic velocities considerably higher than those predicted by the McNab-Meisen relation are required to obtain numerical results in full agreement with the experimental data available for buoyancy-driven flows of enclosed nanofluids, as shown by Aminfar and Haghgoo (2012), which is fully in line with the earlier findings of Giddings et al. (1995). Furthermore, the fact that the thermophoretic velocity predicted by the McNab-Meisen relation is independent of the amount of the suspended solid phase does not seem to be so much realistic, also taking into due account the results obtained for polymer solutions by Zhang et al. (1999), and by Rauch et al. (2007), who discovered that the thermophoretic diffusion coefficient decreased markedly as the concentration of the solution was increased.

Additional studies with a bearing on the subject discussed above are for example those performed by Noghrehabadi et al. (2015), Sheremet and Chinnasamy (2018), and Alsabery et al. (2018).

Framed in this general background, a numerical study on natural convection from a pair of differentially heated horizontal cylinders set side by side in a nanofluid-filled adiabatic square enclosure, inclined with respect to gravity so that the heated cylinder is located below the cooled one, is performed. Simulations are carried out using a two-phase model based on the double-diffusive approach accounting for the contribution of the Brownian diffusion and thermophoresis to the relative motion between the solid and liquid phases, in which, in particular, the coefficient of thermophoretic diffusion of the suspended nanoparticles is calculated through an empirical correlation based on a high number of literature experimental data. Main scope of the present paper is to evaluate in what measure the size and average volume fraction of the suspended solid phase, as well as the tilting angle of the enclosure, the average temperature of the nanofluid and the center-to-center separation distance between the cylinders, affect the nanofluid heat transfer performance, and also to discuss the basic heat and fluid flow features.
Buoyancy-
induced
convection

3165 
$\mathrm{HFF}$

30,6

\section{6}

Figure 1.

Sketch of the geometry, boundary conditions and coordinate systems

\section{Mathematical formulation}

A square enclosure of width $W$, containing a pair of horizontal cylinders of radius $R$, set side by side at a center-to-center separation distance $L$, is filled with a water-based nanofluid with suspended alumina nanoparticles $\left(\mathrm{Al}_{2} \mathrm{O}_{3}+\mathrm{H}_{2} \mathrm{O}\right)$. The cylinders are kept at two different uniform temperatures $T_{h}$ and $T_{c}\left(T_{h}>T_{c}\right)$, while the four walls of the cavity are assumed to be perfectly insulated. The cavity is inclined of an angle $\gamma$ with respect to gravity so that the heated cylinder is located below the cooled one, as sketched in Figure 1, in which the reference polar and Cartesian coordinate systems, for the cylinders and the cavity, respectively, are also represented. The resulting buoyancy-induced flow is considered to be two-dimensional and laminar, with negligible viscous dissipation and pressure work. It is assumed that the suspended nanoparticles and the base liquid are in local thermal equilibrium, and that the Brownian diffusion and thermophoresis are the only slip mechanisms by which the nanoparticles can develop a significant relative velocity with respect to the base liquid, as discussed by Buongiorno (2006). Another assumption made in the derivation of the model is that the effective properties of the nanofluid vary with temperature, other than being locally dependent on the concentration of the suspended solid phase. Finally, the heat transfer associated with the nanoparticle motion relative to the base fluid, as well as radiative heat transfer, is neglected.

In these hypotheses, the governing equations of continuity, momentum and energy for the nanofluid, and the equation of continuity for the nanoparticles, reduce to:

$$
\begin{gathered}
\frac{\partial \rho_{n}}{\partial t}+\nabla \cdot\left(\rho_{n} \mathbf{V}\right)=0 \\
\frac{\partial\left(\rho_{n} \mathbf{V}\right)}{\partial t}+\nabla \cdot\left(\rho_{n} \mathbf{V V}\right)=\nabla \cdot \tau+\rho_{n} \mathbf{g} \\
\frac{\partial\left(\rho_{n} c_{n} T\right)}{\partial t}+\nabla \cdot\left(\rho_{n} \mathbf{V} c_{n} T\right)=\nabla \cdot\left(k_{n} \nabla T\right) \\
\frac{\partial\left(\rho_{n} m\right)}{\partial t}+\nabla \cdot\left(\rho_{n} \mathbf{V} m\right)=-\nabla \cdot \mathbf{J}_{p},
\end{gathered}
$$

where $t$ is the time, $\mathbf{V}$ is the velocity vector having $\mathrm{x}$-wise and $\mathrm{y}$-wise components $\mathrm{U}$ and $\mathrm{V}, \boldsymbol{\tau}$ is the stress tensor, $\mathbf{g}$ is the gravity vector, $\mathbf{J}_{\mathrm{p}}$ is the nanoparticle diffusion mass flux, $T$ is the temperature, $m$ is the mass fraction (also called concentration) of the suspended

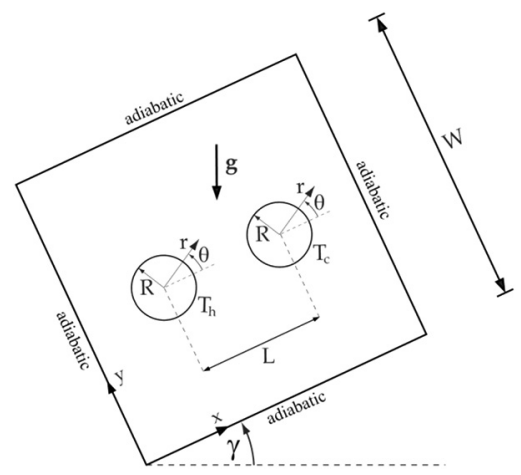


nanoparticles, $\rho_{n}$ is the effective mass density, $c_{n}$ is the effective specific heat at constant pressure, and $k_{n}$ is the effective thermal conductivity. Assuming that the nanofluid has a Newtonian behaviour - as demonstrated by Das et al. (2003), Prasher et al. (2006), He et al. (2007), Chen et al. (2007), Chevalier et al. (2007) and Cabaleiro et al. (2013), just to cite a few -, induced the stress tensor can be expressed as:

$$
\tau=-\left(p+\frac{2}{3} \mu_{n} \nabla \cdot \mathbf{V}\right) \mathbf{I}+\mu_{n}\left[\nabla \mathbf{V}+(\nabla \mathbf{V})^{\mathrm{t}}\right]
$$

where $p$ is the pressure, $\mu_{n}$ is the effective dynamic viscosity and $\mathbf{I}$ is the unit tensor. Superscript $t$ indicates the transpose of $\nabla \mathbf{V}$. The nanoparticle diffusion mass flux is calculated as the sum of the Brownian and thermophoretic diffusion terms in the hypothesis of dilute mixture (i.e. low mass fraction), thus obtaining:

$$
\mathbf{J}_{p}=-\rho_{n}\left(D_{B} \nabla m+D_{T} \frac{\nabla T}{T}\right)
$$

where $D_{B}$ and $D_{T}$ are the Brownian and thermophoretic diffusion coefficients, respectively.

At this stage, it seems worth pointing out that the relation existing between the nanoparticle mass fraction, $m$, and the most widely used nanoparticle volume fraction, $\varphi$, is:

$$
\rho_{s} \phi=\rho_{n} m
$$

where $\rho_{S}$ is the mass density of the solid phase.

The Brownian diffusion coefficient, $D_{B}$, is given by the Stokes-Einstein equation (Einstein, 1905):

$$
D_{B}=\frac{k_{b} T}{3 \pi \mu_{f} d_{p}}
$$

in which $k_{b}=1.38066 \times 10^{-23} \mathrm{~J} / \mathrm{K}$ is the Boltzmann constant, $\mu_{f}$ is the dynamic viscosity of the base fluid and $d_{p}$ is the diameter of the suspended nanoparticles.

The thermophoretic diffusion coefficient, $D_{T}$, is expressed as:

$$
D_{T}=S_{T} \frac{\mu_{f}}{\rho_{f}} m
$$

where $\rho_{f}$ is the mass density of the base liquid, and $S_{T}$ is the so-called thermophoresis parameter, that, for water-based nanofluids containing metal-oxide nanoparticles, can be evaluated by the following correlation developed by Corcione et al. (2015) on the basis of experimental heat transfer data-sets reported in the literature by different research teams:

$$
S_{T}=\left[\left(1.5 \times 10^{4}\right)\left(\frac{k_{s}}{k_{f}}\right)^{-3}+0.9\right] \cdot\left[-16\left(\phi_{a v}\right)^{2.35}+0.0195\right],
$$

in which $k_{s}$ and $k_{f}$ are the thermal conductivities of the solid nanoparticles and the base fluid, and $\varphi_{a v}$ is the average volume fraction of the suspended nanoparticles. 
HFF

30,6

3168

The effective thermal conductivity, $k_{n}$, and the effective dynamic viscosity, $\mu_{n}$, can be predicted using the following correlations produced by Corcione (2011) using a wide number of experimental data obtained by several research groups:

$$
\frac{k_{n}}{k_{f}}=1+4.4 \operatorname{Re}_{p}^{0.4} \operatorname{Pr}_{f}^{0.66}\left(\frac{T}{T_{f r}}\right)^{10}\left(\frac{k_{s}}{k_{f}}\right)^{0.03} \phi^{0.66}
$$

$$
\frac{\mu_{n}}{\mu_{f}}=\frac{1}{1-34.87\left(d_{p} / d_{f}\right)^{-0.3} \phi^{1.03}},
$$

where $\mathrm{Re}_{p}$ is the nanoparticle Reynolds number, $\operatorname{Pr}_{f}$ is the Prandtl number of the base fluid, $T_{f r}$ is the freezing point of the base liquid and $d_{f}$ is the equivalent diameter of a base fluid molecule.

The nanoparticle Reynolds number is given by:

$$
\operatorname{Re}_{p}=\frac{\rho_{f} u_{p} d_{p}}{\mu_{f}}
$$

in which $u_{p}$ is the nanoparticle Brownian velocity calculated as the ratio between $d_{p}$ and the time $t_{D}$ required to cover such a distance, that, according to Keblinski et al. (2002), is:

$$
t_{D}=\frac{d_{p}^{2}}{6 D_{B}},
$$

where $D_{B}$ is the Brownian diffusion coefficient defined in equation (8). Hence:

$$
\operatorname{Re}_{p}=\frac{2 \rho_{f} k_{B} T}{\pi \mu_{f}^{2} d_{p}}
$$

The equivalent diameter of a base fluid molecule is calculated at the reference temperature $T_{o}=293 \mathrm{~K}$ on the basis of the relation $M=\rho_{f o} V_{m} N$, where $M, \rho_{f o}$ and $V_{m}$ are the molar mass, the mass density at temperature $T_{O}$ and the molecular volume of the base fluid, while $N=6.022 \mathrm{~s}^{2} 10^{23} \mathrm{~mol}^{-1}$ is the Avogadro number. If we express $V_{m}$ as $(4 / 3) \pi\left(d_{f} / 2\right)^{3}$, we obtain:

$$
d_{f}=0.1\left[\frac{6 M}{N \pi \rho_{f 0}}\right]^{1 / 3}
$$

The effective mass density, $\rho_{n}$, and the effective specific heat at constant pressure, $c_{n}$, are calculated by the customary mixing theory:

$$
\begin{gathered}
\rho_{n}=(1-\phi) \rho_{f}+\phi \rho_{s} \\
c_{n}=\frac{(1-\phi)(\rho c)_{f}+\phi(\rho c)_{s}}{(1-\phi) \rho_{f}+\phi \rho_{s}},
\end{gathered}
$$

in which $(\rho c)_{f}$ and $(\rho c)_{s}$ are the heat capacities at constant pressure per unit volume of the base fluid and the solid nanoparticles. The validity of equations (17) and (18) was confirmed experimentally by Pak and Cho (1998), and by Zhou and Ni (2008), respectively. 
The assigned boundary conditions are:

- $T=T_{h}, \mathbf{V}=0$ and $\mathbf{J}_{\mathbf{p}}=0$ at the heated cylinder surface;

- $T=T_{c}, \mathbf{V}=0$ and $\mathbf{J}_{\mathbf{p}}=0$ at the cooled cylinder surface; and

Buoyancyinduced

- $\partial T / \partial n=0, \mathbf{V}=0$ and $\mathbf{J}_{\mathbf{p}}=0$ at the cavity walls, where $n$ denotes the normal to the wall.

The initial conditions assumed throughout the enclosure are:

- $\quad$ nanofluid at rest, i.e., $\mathbf{V}=0$;

- uniform average temperature of the nanofluid, $T_{a v}=\left(T_{h}+T_{c}\right) / 2$; and

- assigned uniform average mass fraction of the suspended nanoparticles, $m_{a v}$.

\section{Computational procedure}

The system of the governing equations defined by equations (1)-(4), in conjunction with the boundary and initial conditions stated earlier, is solved through the application of a finitevolume method. The pressure-velocity coupling is handled using the SIMPLE-C algorithm introduced by Van Doormaal and Raithby (1984), which is essentially a more implicit variant of the SIMPLE algorithm developed by Patankar and Spalding (1972), whose details are thoroughly described in Patankar (1980). Convective terms are approximated through the QUICK discretization scheme proposed by Leonard (1979), whereas a second-order implicit backward scheme is applied for time integration.

According to the geometry of the system, a cylindrical polar grid is employed around each cylinder, whilst a Cartesian grid is used to fill the remainder of the integration domain. The polar and Cartesian grids, which are entirely independent of one another, overlap with no attempt of node-matching, their connection being provided by a row of false nodes, in which the values of the dependent variables are calculated by a linear interpolation of their values at the four surrounding real nodes, as depicted in Figure 2 and discussed in full details in a couple of papers authored by Corcione (2005, 2007). Non-uniform structured grids are used for the discretization of both the polar and the Cartesian grid regions, having a higher concentration of grid nodes around the cylinders as well as in the stagnation regions at the top of the heated cylinder and the bottom of the cooled cylinder, and a relatively lower uniform spacing elsewhere. Time discretization is chosen uniform.

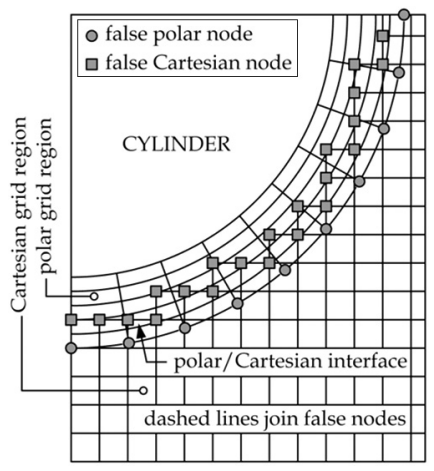

Figure 2.

Sketch of the polar/ Cartesian discretization grid systems 
HFF

30,6

Starting from the assigned initial fields of the dependent variables, at each time-step the system of the discretized algebraic governing equations is solved iteratively by the way of a line-by-line application of the Thomas algorithm. A standard under-relaxation technique is enforced in all steps of the computational procedure to ensure an adequate convergence. Within each time-step, the numerical solution of the velocity, temperature and concentration fields is considered to be converged when the maximum absolute value of the mass source, as well as the relative changes of the dependent variables at any grid-node between two consecutive iterations, are smaller than the pre-specified values of $10^{-6}$ and $10^{-7}$, respectively. As time passes, the dynamic behaviour of the system is followed by plotting the phase space trajectories of the dependent variables at some assigned grid nodes, i.e. by plotting the distributions of the local time-derivatives of the dependent variables versus the variables themselves with time as a parameter, whose attractor may be represented by either a fixed point, a limit cycle, a torus or a so-called strange attractor, to visualize the tendency of the system to reach either a steady-state, a periodic, a quasi-periodic or a chaotic solution. In addition, the time distributions of the incoming and outgoing heat transfer rates at the heated and cooled cylinders, as well as their relative difference, are continuously monitored to asses the achievement of an asymptotic solution.

At each time-step, after the spatial convergence is satisfactorily attained, the heat fluxes at the heated and cooled cylinders, $q_{h}(t)$ and $q_{c}(t)$, are obtained using the following expressions:

$$
\begin{aligned}
& q_{h}(t)=-\left.\left(k_{n}\right)_{h} \cdot \frac{\partial T}{\partial r}\right|_{r=R}, \\
& q_{c}(t)=-\left.\left(k_{n}\right)_{c} \cdot \frac{\partial T}{\partial r}\right|_{r=R},
\end{aligned}
$$

where $\left(k_{n}\right)_{h}$ and $\left(k_{n}\right)_{c}$ are the values of the effective thermal conductivity at temperatures $T_{h}$ and $T_{c}$, respectively. The local temperature gradients at the heated and cooled cylinders at time $t$ are evaluated by a second-order temperature profile embracing the wall-node and the two subsequent fluid-nodes. The corresponding heat transfer rates at time $t$ are calculated as:

$$
\begin{aligned}
& Q_{h}(t)=\int_{0}^{2 \pi}-\left.\left(k_{n}\right)_{h} \cdot \frac{\partial T}{\partial r}\right|_{r=R} R d \theta \\
& Q_{c}(t)=\int_{0}^{2 \pi}-\left.\left(k_{n}\right)_{c} \cdot \frac{\partial T}{\partial r}\right|_{r=R} R d \theta,
\end{aligned}
$$

in which the integrals are calculated numerically by means of the trapezoidal rule.

Time-integration is stopped once an asymptotic solution, either stationary or periodic, is reached.

When a steady state is achieved, the heat transfer rates at the heated and cooled cylinders, $Q_{h}$ and $Q_{c}$, coincide with the last values computed for $Q_{h}(t)$ and $Q_{c}(t)$ : 


$$
\begin{aligned}
& Q_{h}(t)=\left.Q_{h}(t)\right|_{t \rightarrow \infty} \\
& Q_{c}(t)=\left.Q_{c}(t)\right|_{t \rightarrow \infty}
\end{aligned}
$$

Conversely, when a periodic solution is attained, $Q_{h}$ and $Q_{c}$ are evaluated as:

$$
\begin{aligned}
& Q_{h}=\frac{1}{\Omega} \int_{0}^{\Omega} Q_{h}(t) d t \\
& Q_{c}=\frac{1}{\Omega} \int_{0}^{\Omega} Q_{c}(t) d t,
\end{aligned}
$$

where $\Omega$ is the period of oscillation computed by the solution algorithm.

On the other hand, for both stationary and periodic solutions the following relation holds:

$$
Q_{h}=-Q_{c}=Q
$$

where $Q$ is the rate of heat transferred between the cylinders.

Numerical tests related to the dependence of the results on the mesh spacing and time stepping have been methodically performed for several combinations of the independent variables. Of course, the nanofluid average temperature, $T_{a v}$, in conjunction with the temperature difference between the cylinders, $\Delta T$, may be taken as independent variables instead of $T_{c}$ and $T_{h}$. Additionally, the average volume fraction of the suspended nanoparticles, $\varphi_{a v}$, may be used as an independent variable instead of $m_{a v}$, owing to the following relation derived by combining equations (7) and (17):

$$
\phi_{a v}=\left[\left(\frac{1}{m_{a v}}-1\right) \frac{\rho_{s}}{\rho_{f}}+1\right]^{-1},
$$

in which the values of the mass densities $\rho_{s}$ and $\rho_{f}$ are calculated at temperature $T_{a v}$.

The discretization grids and time-steps used for computations are chosen in such a way that further refinements do not produce noticeable modifications both in the heat transfer rates and in the flow and volume fraction fields. Specifically, the percentage changes of the heat transfer rate $Q$, those of the maximum velocity components $U_{\max }$ and $V_{\max }$ on the $y$-wise and $x$-wise midplanes of the enclosure, and those of the maximum and minimum nanoparticle volume fractions $\varphi_{\max }$ and $\varphi_{\min }$ on the $x$-wise midplane of the enclosure, must be smaller than the pre-established accuracy value of 1 per cent. The typical number of nodal points $(r \times \theta)$ and $(x \times y)$ of the polar and Cartesian discretization grids used for simulations lie in the ranges between $50 \times 140$ and $80 \times 180$, and between $140 \times 140$ and $200 \times 200$, respectively. Moreover, typical time-steps used for simulations lie in the range between $10^{-3} \mathrm{~s}$ and $10^{-2} \mathrm{~s}$. Selected results of the grid and time-step sensitivity analysis are presented in Tables I-III for assigned values of $\Delta T, W$ and $R$, using $\varphi_{a v}, \gamma, d_{p}, T_{a v}$ and $\lambda=$ $L / W$ as controlling parameters. 
HFF

30,6

3172

Finally, with the scope to validate the numerical code used for the present study, four tests have been carried out. In the first test, the steady-state solutions obtained for an airfilled square enclosure differentially heated at sides, assuming $m_{a v}=0$ and constant physical properties, have been compared with the benchmark solutions of de Vahl Davis (1983) and other authors, i.e. Mahdi and Kinney (1990), Hortmann et al. (1990) and Wan et al. (2001). In the second test, the average Nusselt numbers computed numerically for a Prandt1 number $\operatorname{Pr}=7$ (which means water at $T_{a v}=293 \mathrm{~K}$ ) and Rayleigh numbers $\operatorname{Ra}=$ $10^{3}-5 \times 10^{7}$ (calculated using a fixed $\Delta \mathrm{T}=20 \mathrm{~K}$ ) assuming $m_{a v}=0$ have been compared with the usually recommended Berkovsky-Polevikov correlation based on experimental and numerical data of laminar natural convection in vertical rectangular cavities heated and cooled from the side with an aspect ratio near unity, see, e.g. Bejan (2004) and Incropera et al. (2007). In the third test, the steady-state solutions computed for the double-diffusive laminar natural convection occurring inside a square enclosure filled with binary fluids having

\begin{tabular}{|c|c|c|c|c|c|c|c|c|c|}
\hline$\gamma$ & $\varphi_{\mathrm{av}}$ & $\begin{array}{l}\mathrm{d}_{\mathrm{p}} \\
(\mathrm{nm})\end{array}$ & $\begin{array}{l}\text { Mesh size } \\
(\mathrm{r} \times \theta)\end{array}$ & $\begin{array}{c}\text { Mesh size } \\
(\mathrm{x} \times \mathrm{y})\end{array}$ & $\mathrm{Q}(\mathrm{W})$ & $\begin{array}{c}\mathrm{U}_{\max } \\
\left(\times 10^{3}\right)(\mathrm{m} / \mathrm{s})\end{array}$ & $\begin{array}{c}\mathrm{V}_{\max } \\
\left(\times 10^{3}\right)(\mathrm{m} / \mathrm{s})\end{array}$ & $\varphi_{\max }$ & $\varphi_{\min }$ \\
\hline \multirow[t]{4}{*}{$0^{\circ}$} & 0.02 & 25 & $10 \times 60$ & 80 x 80 & 115.74 & 1.173 & 2.089 & 0.02701 & 0.01550 \\
\hline & & & $20 \times 80$ & $100 \times 100$ & 118.29 & 1.202 & 2.139 & 0.02755 & 0.01519 \\
\hline & & & $30 \times 100$ & $120 \times 120$ & 120.22 & 1.222 & 2.175 & 0.02795 & 0.01497 \\
\hline & & & $40 \times 120$ & $140 \times 140$ & 121.16 & 1.233 & 2.195 & 0.02819 & 0.01484 \\
\hline \multirow[t]{4}{*}{$30^{\circ}$} & 0.02 & 25 & 20 x 80 & $100 \times 100$ & 116.90 & 4.206 & 3.020 & 0.02688 & 0.01582 \\
\hline & & & $30 \times 100$ & $120 \times 120$ & 119.49 & 4.309 & 3.093 & 0.02741 & 0.01551 \\
\hline & & & $40 \times 120$ & $140 \times 140$ & 121.43 & 4.380 & 3.144 & 0.02781 & 0.01528 \\
\hline & & & $50 \times 140$ & $160 \times 160$ & 122.38 & 4.420 & 3.173 & 0.02805 & 0.01515 \\
\hline \multirow{4}{*}{$30^{\circ}$} & 0.04 & 25 & $30 \times 100$ & $120 \times 120$ & 117.30 & 4.145 & 2.801 & 0.04826 & 0.03517 \\
\hline & & & $40 \times 120$ & $140 \times 140$ & 119.90 & 4.236 & 2.869 & 0.04921 & 0.03448 \\
\hline & & & $50 \times 140$ & $160 \times 160$ & 121.85 & 4.305 & 2.916 & 0.04993 & 0.03398 \\
\hline & & & $60 \times 160$ & $180 \times 180$ & 122.80 & 4.339 & 2.943 & 0.05036 & 0.03368 \\
\hline \multirow[t]{4}{*}{$30^{\circ}$} & 0.04 & 75 & $40 \times 120$ & $140 \times 140$ & 117.59 & 4.638 & 2.984 & 0.05858 & 0.02486 \\
\hline & & & $50 \times 140$ & $160 \times 160$ & 120.19 & 4.762 & 3.057 & 0.05974 & 0.02427 \\
\hline & & & $60 \times 160$ & $180 \times 180$ & 122.15 & 4.835 & 3.107 & 0.06060 & 0.02397 \\
\hline & & & $80 \times 180$ & $200 \times 200$ & 123.10 & 4.878 & 3.136 & 0.06113 & 0.02388 \\
\hline
\end{tabular}

Table I.

Grid sensitivity

analysis for $\mathrm{T}_{\mathrm{av}}=$

$315 \mathrm{~K}, \lambda=0.3$,

$\Delta \mathrm{t}=5 \times 10^{-3} \mathrm{~s}$

\begin{tabular}{|c|c|c|c|c|c|c|c|c|}
\hline $\mathrm{T}_{\mathrm{av}}(\mathrm{K})$ & $\lambda$ & $\begin{array}{l}\text { Mesh size } \\
\quad(\mathrm{r} \times \theta)\end{array}$ & $\begin{array}{l}\text { Mesh size } \\
(\mathrm{x} \times \mathrm{y})\end{array}$ & $\mathrm{Q}(\mathrm{W})$ & $\begin{array}{c}\mathrm{U}_{\max } \\
\left(\times 10^{3}\right)(\mathrm{m} / \mathrm{s})\end{array}$ & $\begin{array}{c}\mathrm{V}_{\max } \\
\left(\times 10^{3}\right)(\mathrm{m} / \mathrm{s})\end{array}$ & $\varphi_{\max }$ & $\varphi_{\min }$ \\
\hline \multirow[t]{4}{*}{300} & \multirow[t]{4}{*}{0.3} & $20 \times 80$ & $100 \times 100$ & 96.07 & 3.110 & 2.183 & 0.03155 & 0.01302 \\
\hline & & $30 \times 100$ & $120 \times 120$ & 98.19 & 3.202 & 2.236 & 0.03218 & 0.01276 \\
\hline & & $40 \times 120$ & $140 \times 140$ & 99.79 & 3.261 & 2.273 & 0.03265 & 0.01258 \\
\hline & & $50 \times 140$ & $160 \times 160$ & 100.57 & 3.249 & 2.294 & 0.03293 & 0.01247 \\
\hline \multirow[t]{4}{*}{330} & \multirow[t]{4}{*}{0.3} & $10 \times 60$ & $80 \times 80$ & 140.34 & 3.693 & 5.150 & 0.02385 & 0.01747 \\
\hline & & $20 \times 80$ & $100 \times 100$ & 143.44 & 3.783 & 5.276 & 0.02432 & 0.01713 \\
\hline & & $30 \times 100$ & $120 \times 120$ & 145.78 & 3.846 & 5.363 & 0.02468 & 0.01688 \\
\hline & & $40 \times 120$ & $140 \times 140$ & 146.92 & 3.881 & 5.412 & 0.02489 & 0.01673 \\
\hline \multirow[t]{4}{*}{330} & \multirow[t]{4}{*}{0.6} & $30 \times 100$ & $120 \times 120$ & 115.08 & 9.790 & 13.705 & 0.02380 & 0.01411 \\
\hline & & $40 \times 120$ & $140 \times 140$ & 117.62 & 10.079 & 14.109 & 0.02450 & 0.01369 \\
\hline & & $50 \times 140$ & $160 \times 160$ & 119.54 & 10.266 & 14.372 & 0.02496 & 0.01344 \\
\hline & & $60 \times 160$ & $180 \times 180$ & 120.47 & 10.363 & 14.507 & 0.02519 & 0.01331 \\
\hline
\end{tabular}

Table II.

Grid sensitivity analysis for $\varphi_{\mathrm{av}}=$ $0.02, \gamma=30^{\circ}, \mathrm{d}_{\mathrm{p}}=$ $25 \mathrm{~nm}, \Delta \mathrm{t}=5 \times 10^{-3} \mathrm{~s}$ 
constant physical properties, subjected to simultaneous horizontal temperature and concentration gradients, have been compared with the numerical results of Béghein $e t$ al. (1992), Gobin and Bennacer (1996) and Bennacer and Gobin (1996). In the fourth test, the whole computational code has been applied to reproduce numerically six sets of experiments performed using differentially heated vertical enclosures filled with $\mathrm{Al}_{2} \mathrm{O}_{3}+\mathrm{H}_{2} \mathrm{O}$ by Putra et al. (2003) for $\varphi_{a v}=0.01$ and 0.04, Chang et al. (2008) for $\varphi_{a v}=0.0131$ and 0.0272 , and $\mathrm{Hu}$ et al. (2014) for $\varphi_{a v}=0.0025$ and 0.0077 . A good degree of agreement between our numerical results and the literature data was achieved in any validation test carried out, as e.g. displayed for the fourth test in Figure 3, in which the numerical solutions obtained for the ratio between the average Nusselt numbers of the nanofluid and the pure base fluid, $\mathrm{Nu}_{\mathrm{n}} /$ $\mathrm{Nu}_{\mathrm{f}}$, plotted versus the Rayleigh number of the nanofluid, $\mathrm{Ra}_{\mathrm{n}}$, are compared with the corresponding experimental values.

\section{Results and discussion}

Numerical simulations are performed using alumina/water nanofluids for different values

of:

- the average volume fraction of the suspended solid phase, $\varphi_{a v}$, in the range between 0 and 0.04;

- the tilting angle of the enclosure, $\gamma$, in the range between $0^{\circ}$ and $70^{\circ}$;

- the average diameter of the nanoparticles, $d_{p}$, in the range between $25 \mathrm{~nm}$ and 75 $\mathrm{nm}$;

- the average nanofluid temperature, $T_{a v}$, in the range between $300 \mathrm{~K}$ and $330 \mathrm{~K}$; and

- the dimensionless center-to-center separation distance between the cylinders, $\lambda=$ $L / W$, in the range between 0.3 and 0.6 .

The temperature difference imposed between the cylinders, the width of the enclosure and the cylinder radius have been set to $\Delta T=10 \mathrm{~K}, W=0.04 \mathrm{~m}$ and $R=0.004 \mathrm{~m}$ for all the simulations executed.

Selected typical local results are reported in Figure 4, in which steady-state streamline, isotherm and isoconcentration contours relative to different tilting angles $\gamma=0^{\circ}, 30^{\circ}$ and $60^{\circ}$ are plotted for $\varphi_{a v}=0.02, d_{p}=25 \mathrm{~nm}, T_{a v}=315 \mathrm{~K}$ and $\lambda=0.4$. It is apparent that, for any tilting angle considered, the flow field consists of a primary circulation occurring between the cylinders, due to the rise of the hot nanofluid adjacent to the heated cylinder and its descent past the opposite cooled cylinder, and of a secondary circulation, driven by the same imposed temperature difference, that embraces both cylinders. Moreover, the combined effects of the nanofluid motion due to the imposed differential heating, and the diffusion of the suspended nanoparticles in the direction from hot to cold, give rise to the formation of a low-concentration boundary layer adjacent to the heated cylinder surface, and a high-concentration boundary layer adjacent to the cooled cylinder surface. This means

\begin{tabular}{|c|c|c|c|c|c|c|c|}
\hline Mesh size $(\mathrm{r} \times \theta)$ & $\begin{array}{l}\text { Mesh size } \\
(\mathrm{x} \times \mathrm{y})\end{array}$ & $\Delta \mathrm{t}(\mathrm{s})$ & $\mathrm{Q}(\mathrm{W})$ & $\begin{array}{c}\mathrm{U}_{\max } \\
\left(\times 10^{3}\right)(\mathrm{m} / \mathrm{s})\end{array}$ & $\begin{array}{c}\mathrm{V}_{\max } \\
\left(\times 10^{3}\right)(\mathrm{m} / \mathrm{s})\end{array}$ & $\varphi_{\max }$ & $\varphi_{\min }$ \\
\hline \multirow[t]{4}{*}{$50 \times 140$} & \multirow[t]{4}{*}{$160 \times 160$} & $10^{-1}$ & 116.51 & 4.201 & 3.031 & 0.02589 & 0.01592 \\
\hline & & $5 \times 10^{-2}$ & 119.08 & 4.275 & 3.069 & 0.02713 & 0.01567 \\
\hline & & $10^{-2}$ & 121.05 & 4.362 & 3.131 & 0.02768 & 0.01536 \\
\hline & & $5 \times 10^{-3}$ & 122.38 & 4.420 & 3.173 & 0.02805 & 0.01515 \\
\hline
\end{tabular}
.
Buoyancyinduced convection

3173 


\section{HFF \\ 30,6}

\section{4}

Figure 3.

Comparison between the numerical values obtained for $\mathrm{Nu}_{\mathrm{n}} / \mathrm{Nu}_{\mathrm{f}}$ and the corresponding experimental data of Putra et al. (2003), Chang et al. (2008) and Hu et al. (2014) for $\mathrm{Al}_{2} \mathrm{O}_{3}+\mathrm{H}_{2} \mathrm{O}$ in differentially heated vertical enclosures
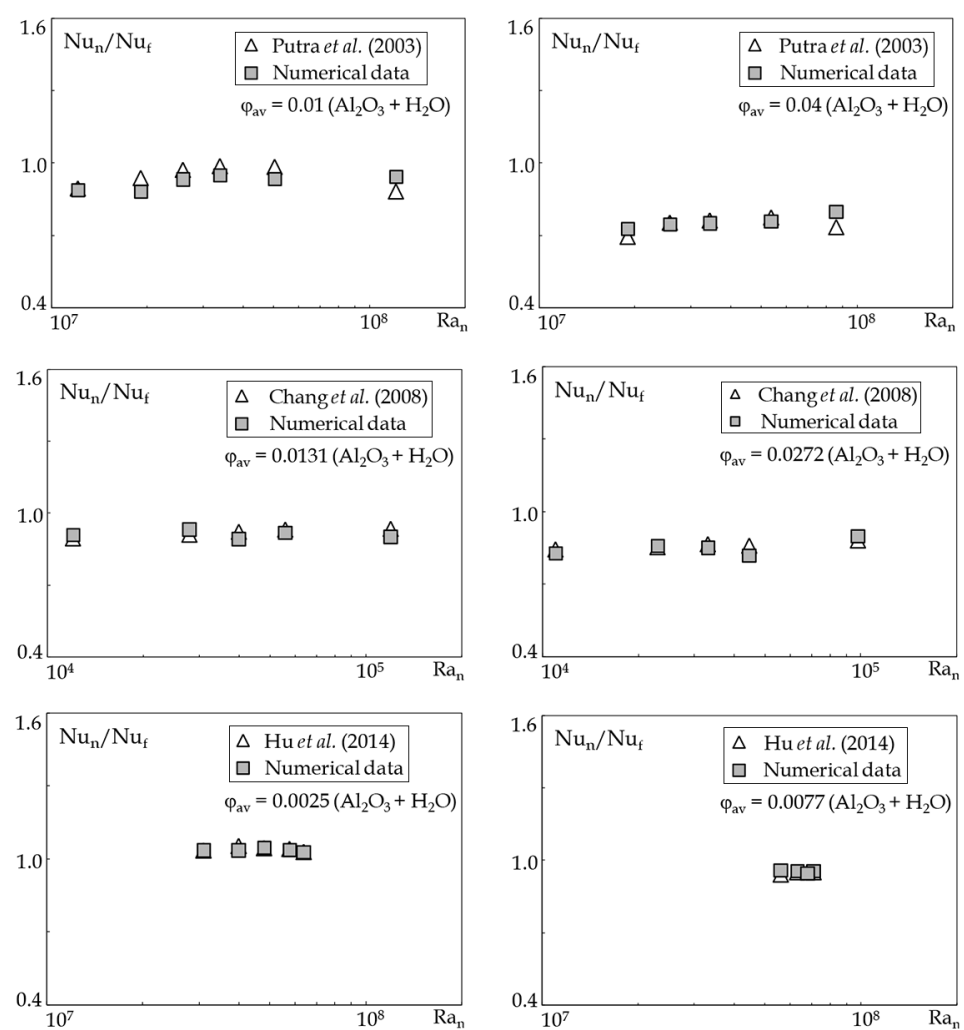

that a concentration gradient establishes across the enclosure, whose role in determining the heat transfer performance of the nanofluid needs being discussed. In fact, the nanofluid behaviour is primarily affected by the two opposite effects arising from the increase of both the thermal conductivity and the dynamic viscosity produced by the dispersion of the nanoparticles into the base liquid. The first effect, which tends to enhance the nanofluid heat transfer performance, prevails at small volume fractions of the suspended solid phase, whereas the second effect, which tends to degrade the nanofluid heat transfer performance, prevails at higher volume fractions. On the other hand, due to the mentioned concentration gradient, a cooperating solutal driving force arises. The situation is such that, as a rule, this extra-buoyancy tends to compensate the increased friction consequent to the dynamic viscosity growth, thus implying that the beneficial effect of the increased thermal conductivity plays the major role in determining the heat transfer performance of the nanofluid. Hence, owing to the strong dependence of the effective thermal conductivity on temperature, a pronounced heat transfer enhancement has to be expected at high average temperatures, as shown in Figure 5, where a number of distributions of the ratio between the heat transfer rates across the nanofluid and the pure base fluid, $Q_{n} / Q_{f}$, are plotted versus $\varphi_{a v}$ for the horizontal alignment, i.e. $\gamma=0^{\circ}$, using $T_{a v}$ as a parameter. It can be noticed that the amount of heat exchanged by the nanofluid may be significantly higher than that exchanged by the pure base liquid, which is what happens at $T_{a v}=330 \mathrm{~K}$ and $\varphi_{a v}=0.04$, that, for the examined configuration, corresponds to a 18 per cent enhancement. On the other 

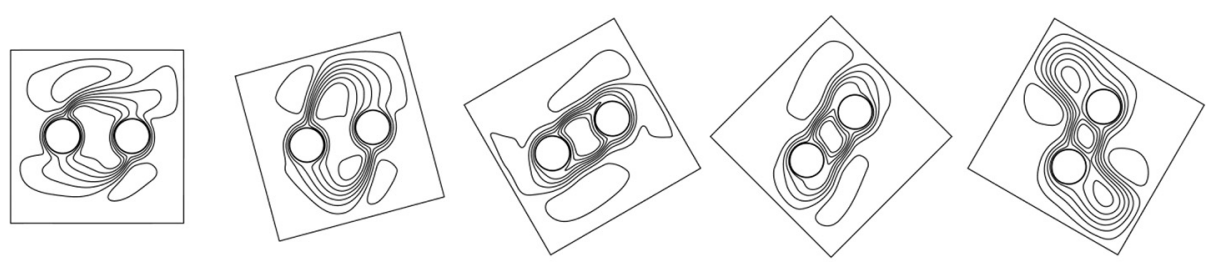

Buoyancyinduced convection
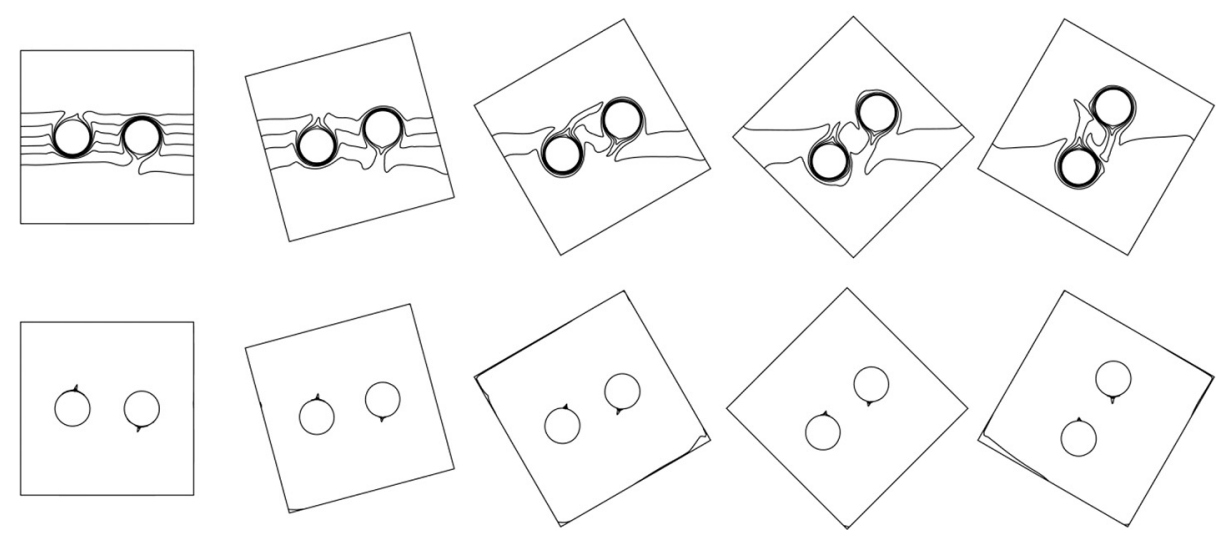

3175

hand, at lower average temperatures, e.g. $T_{a v}=300 \mathrm{~K}$, the limited increase of the thermal conductivity gives rise to a different situation. In fact, the dispersion of a progressively larger amount of nanoparticles into the base liquid results in a mild increase of the ratio $Q_{n} /$ $Q_{f}$ up to a point, which is due to the prevailing effect of the increased thermal conductivity. The value of $\varphi_{a v}$ corresponding to the peak of $Q_{n} / Q_{f}$ can be identified as the optimal particle loading for maximum heat transfer, $\varphi_{o p t}$. As $\varphi_{a v}$ is further increased above $\varphi_{o p t}$, the ratio $Q_{n} / Q_{f}$ decreases, which is a direct consequence of the prevailing effect of the growth of the dynamic viscosity. When the increased viscosity effect outweighs the increased thermal

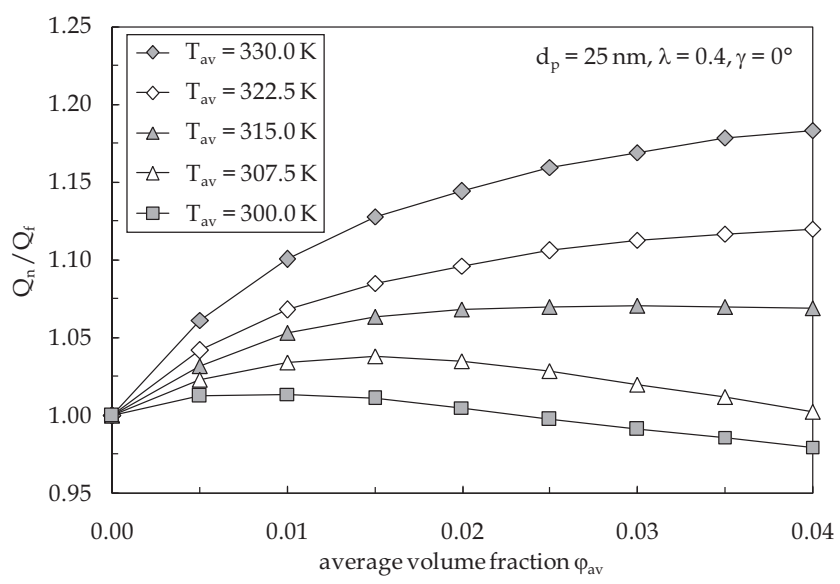

Figure 5.

Distributions of $\mathrm{Q}_{\mathrm{n}} / \mathrm{Q}_{\mathrm{f}}$ vs. $\varphi_{\text {av }}$ for $\mathrm{d}_{\mathrm{p}}=$ $25 \mathrm{~nm}, \lambda=0.4$ and $\gamma=0^{\circ}$, using $\mathrm{T}_{\mathrm{av}}$ as a parameter 
$\mathrm{HFF}$

30,6

\section{6}

\section{Figure 6.}

Distributions of $\mathrm{Q}_{\mathrm{n}} / \mathrm{Q}_{\mathrm{f}}$ vs. $\varphi_{\text {av }}$ for $\mathrm{d}_{\mathrm{p}}=$ $25 \mathrm{~nm}, \mathrm{~T}_{\mathrm{av}}=315 \mathrm{~K}$ and $\lambda=0.4$, using $\gamma$ as a parameter conductivity effect, the ratio $Q_{n} / Q_{f}$ becomes lower than unity, thus meaning that the heat transfer rate across the nanofluid is lower than that across the pure base liquid, and thus the use of the nanofluid is detrimental.

As the tilting angle $\gamma$ is increased, the increase of the cooperating solutal driving force, as well as the increase of the vertical path available for the acceleration of the nanofluid, results in a growth of the motion intensity, which enhances the heat transfer performance. On the other hand, as $\gamma$ is further increased, the interactions occurring between the hot and cold plumes result in a significant decrease of the heat transfer rate. A set of distributions of $Q_{n} / Q_{f}$ plotted versus $\varphi_{a v}$ using $\gamma$ as a parameter is reported in Figure 6, showing the existence of an optimal tilting angle of the enclosure for maximum heat transfer.

Additionally, the effects of the center-to-center separation distance between the cylinders and the nanoparticle diameter on the heat transfer performance are pointed out in Figures 7 and 8, in which, for any independent variable, a number of distributions of $Q_{n} / Q_{f}$ are plotted versus $\varphi_{a v}$ for $\gamma=30^{\circ}$ using the variable itself as a parameter. Besides the fact that both controlling variables have moderate effects, it is apparent that $Q_{n} / Q_{f}$ increases as $\lambda$ is increased and $d_{p}$ is decreased.

Finally, it seems worth noticing that for inclination angles larger than $60^{\circ}$, periodic solutions can be achieved, as for example shown in Figure 9, in which the asymptotic time-distribution of the heat transfer rate at the heated cylinder during one period of oscillation, and the related Fourier frequency spectrum of the amplitude of oscillation, are displayed for $\varphi_{a v}=0.02, d_{p}=$ $25 \mathrm{~nm}, T_{a v}=315 \mathrm{~K}, \lambda=0.4$ and $\gamma=65^{\circ}$. The corresponding time-evolution of the isotherm contours are documented in Figure 10 through five snapshots which span across one period of oscillation, showing that the formation of a low-concentration region located below a highconcentration region gives rise to a solutal buoyancy force, whose competition with the thermal buoyancy force due to the imposed temperature gradient results in an oscillatory flow.

\section{Conclusions}

Laminar natural convection of nanofluids from a pair of differentially heated horizontal cylinders set side by side in a nanofluid-filled adiabatic square enclosure, inclined with respect to gravity so that the heated cylinder is located below the cooled one, has been investigated numerically. A two-phase model based on the double-diffusive approach has been applied, with the assumption that the slip motion occurring between the solid and liquid phases is basically ascribable to the Brownian diffusion and thermophoresis. The

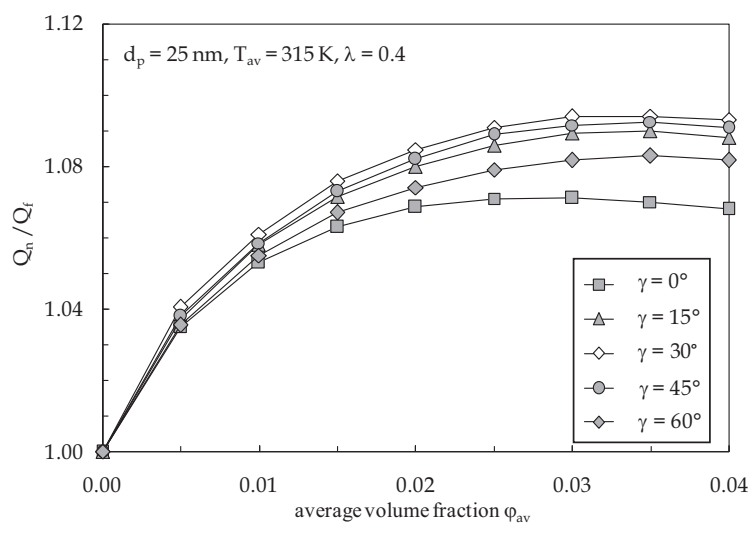


four-equation system of the mass, momentum and energy transfer governing equations has been solved using a computational code incorporating three empirical correlations for the evaluation of the effective thermal conductivity, the effective dynamic viscosity and the coefficient of thermophoretic diffusion, all based on a high number of experimental data available in the literature. The SIMPLE-C algorithm has been used to handle the pressurevelocity coupling.

Simulations have been performed using $\mathrm{Al}_{2} \mathrm{O}_{3}+\mathrm{H}_{2} \mathrm{O}$, for different values of the diameter and the average volume fraction of the suspended nanoparticles, the tilting angle of the enclosure, the average temperature of the nanofluid and the center-to-center separation distance between the cylinders.

The main results obtained may be summarized as follows:

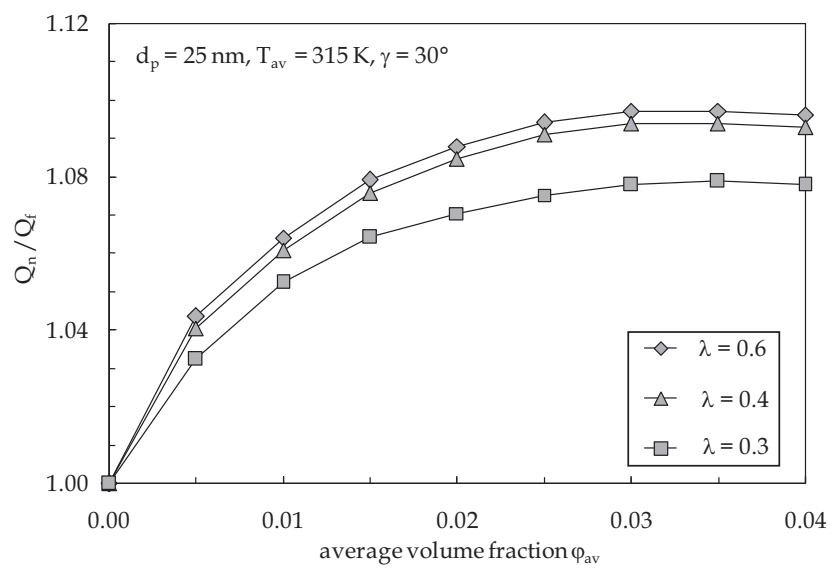

Figure 7. Distributions of $\mathrm{Q}_{\mathrm{n}} / \mathrm{Q}_{\mathrm{f}}$ vs. $\varphi_{\mathrm{av}}$ for $\mathrm{d}_{\mathrm{p}}=$ $25 \mathrm{~nm}, \mathrm{~T}_{\mathrm{av}}=315 \mathrm{~K}$ and $\gamma=30^{\circ}$, using $\lambda$ as a parameter

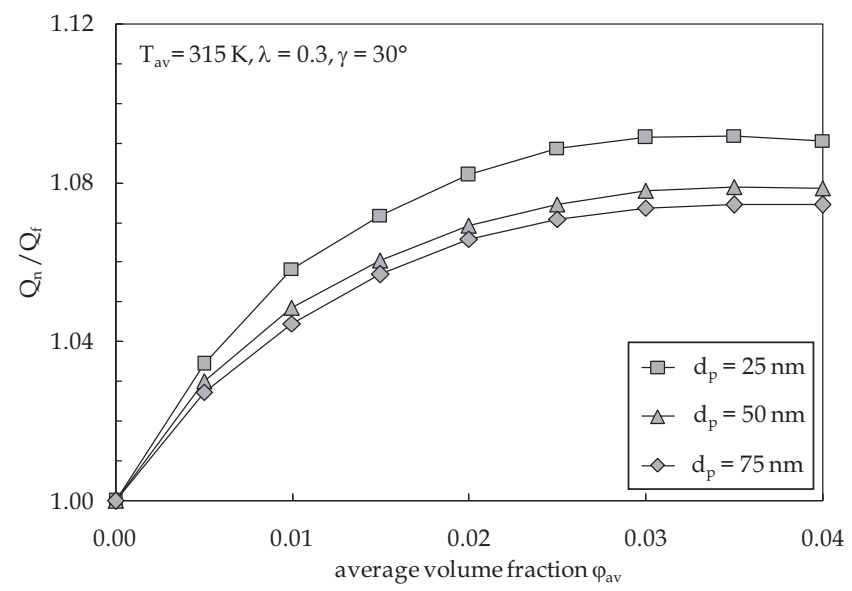

Figure 8. Distributions of $\mathrm{Q}_{\mathrm{n}} / \mathrm{Q}_{\mathrm{f}}$ vs. $\varphi_{\text {av }}$ for $\mathrm{T}_{\mathrm{av}}=$ $315 \mathrm{~K}, \lambda=0.3$ and $\gamma=30^{\circ}$, using $\mathrm{d}_{\mathrm{p}}$ as a parameter 
HFF

30,6

\section{8}

Figure 9.

Asymptotic time distribution of $\mathrm{Q}_{\mathrm{nh}}(\mathrm{t})$ and related Fourier frequency spectrum of the amplitude of oscillation for $\varphi_{\mathrm{av}}=$ $0.02, \mathrm{~d}_{\mathrm{p}}=25 \mathrm{~nm}$, $\mathrm{T}_{\mathrm{av}}=315 \mathrm{~K}, \lambda=0.4$ and $\gamma=65^{\circ}$

- The overall solid phase migration in the direction from hot to cold results in a cooperating solutal buoyancy force which tends to compensate the friction increase consequent to the dynamic viscosity growth due to the dispersion of the nanoparticles into the base fluid;

- The effect of the increased thermal conductivity consequent to the nanoparticle dispersion into the base fluid plays the major role in determining the heat transfer enhancement of the nanofluid, at least in the upper range of the investigated average temperatures;

- At high temperatures, the nanofluid heat transfer performance relative to that of the pure base liquid increases with increasing the average volume fraction of the suspended solid phase, whereas at low temperatures it has a peak at an optimal particle loading;

- The dispersion of the nanoparticles into the base liquid has its maximum effect on the nanofluid heat transfer performance at an optimal tilting angle of the enclosure;

- The relative heat transfer performance of the nanofluid increases notably as the average temperature is increased, and just moderately as the center-to-center separation distance between the cylinders is increased and the nanoparticle size is decreased; and

- At large tilting angles of the enclosure, the formation of a low-concentration region located below a high-concentration region gives rise to a solutal buoyancy force, whose competition with the thermal driving force consequent to the imposed temperature gradient results in an oscillatory flow.
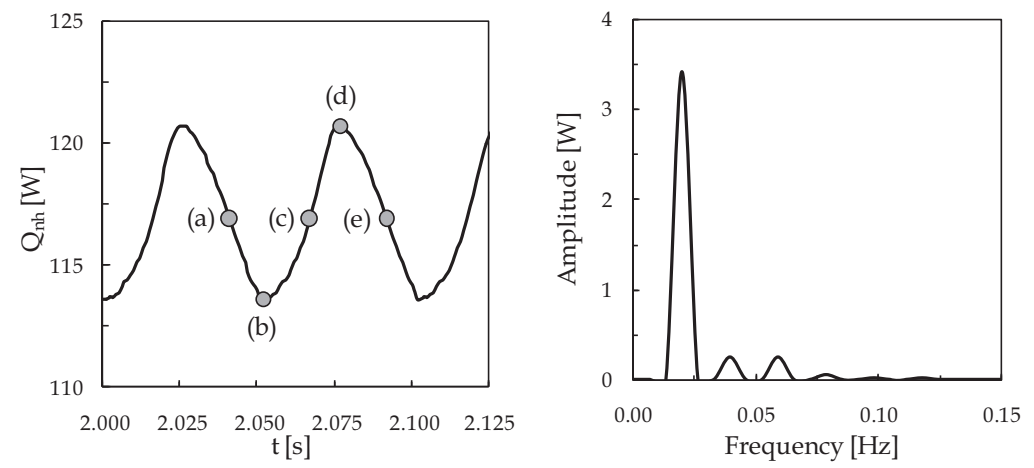

Figure 10.

Asymptotic time evolution of the isotherm contours during one period of oscillation for $\varphi_{\mathrm{av}}=$ $0.02, \mathrm{~d}_{\mathrm{p}}=25 \mathrm{~nm}$, $\mathrm{T}_{\mathrm{av}}=315 \mathrm{~K}, \lambda=0.4$ and $\gamma=65^{\circ}$

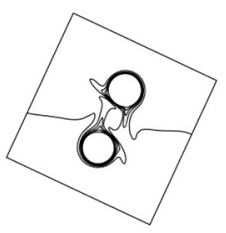

(a)

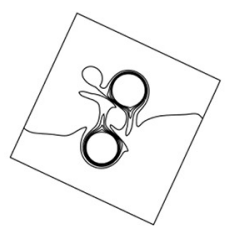

(b)

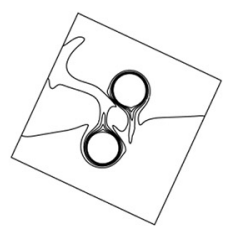

(c)

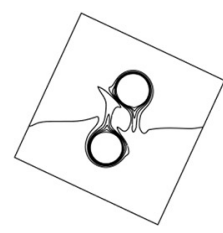

(d)

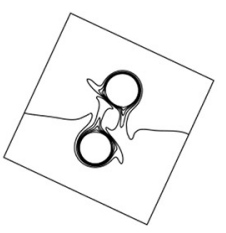

(e) 


\section{References}

Alsabery, A.I., Tayebi, T., Chamkha, A.J. and Hashim, I. (2018), "Effects of two-phase nanofluid model on natural convection in a square cavity in the presence of an adiabatic inner block and magnetic field", International Journal of Numerical Methods for Heat and Fluid Flow, Vol. 28 No. 7 , pp. 1613-1647.

Aminfar, H. and Haghgoo, M.R. (2012), "Brownian motion and thermophoresis effects on natural convection of alumina-water nanofluid”, Journal of Mechanical Engineering Science, Vol. 227 No. 1, pp. 100-110.

Béghein, C., Haghigat, F. and Allard, F. (1992), "Numerical study of double-diffusive natural convection in a square cavity”, International Journal of Heat and Mass Transfer, Vol. 35 No. 4, pp. 833-846.

Bejan, A. (2004), Convection Heat Transfer, 3rd ed., John Wiley and Sons, Hoboken, NJ.

Bennacer, R. and Gobin, D. (1996), "Cooperating thermosolutal convection in encloseres-I. scale analysis and mass transfer", International Journal of Heat and Mass Transfer, Vol. 39 No. 13, pp. 2671-2681.

Buongiorno, J. (2006), "Convective transport in nanofluids", Journal of Heat Transfer, Vol. 128 No. 3, pp. 240-250.

Cabaleiro, D., Pastoriza-Gallego, M.J., Piñero, M.M. and Lugo, L. (2013), "Characterization and measurements of thermal conductivity, density and rheological properties of zinc oxide nanoparticles dispersed in (ethane-1,2-diol + water) mixture", Journal of Chemical Thermodynamics, Vol. 58, pp. 405-415.

Chang, B.H., Mills, A.F. and Hernandez, E. (2008), "Natural convection of microparticlesuspensions in thin enclosures", International Journal of Heat and Mass Transfer, Vol. 51 Nos 5/6, pp. 1332-1341.

Chen, H., Ding, Y., He, Y. and Tan, C. (2007), "Rheological behaviour of ethylene glycol based titania nanofluids", Chemical Physics Letters, Vol. 444 Nos 4/6, pp. 333-337.

Chevalier, J., Tillement, O. and Ayela, F. (2007), "Rheological properties of nanofluids flowing through microchannels", Applied Physics Letters, Vol. 91 No. 23, p. 233103.

Corcione, M. (2005), "Correlating equations for free convection heat transfer from horizontal isothermal cylinders set in a vertical array", International Journal of Heat and Mass Transfer, Vol. 48 No. 17, pp. 3660-3673.

Corcione, M. (2007), "Interactive free convection from a pair of vertical tube-arrays at moderate Rayleigh numbers", International Journal of Heat and Mass Transfer, Vol. 50 Nos 5/6, pp. 1061-1074.

Corcione, M. (2011), "Empirical correlating equations for predicting the effective thermal conductivity and dynamic viscosity of nanofluids", Energy Conversion and Management, Vol. 52 No. 1, pp. 789-793.

Corcione, M., Cianfrini, M. and Quintino, A. (2015), "Enhanced natural convection heat transfer of nanofluids in enclosures with two adjacent walls heated and the two opposite walls cooled", International Journal of Heat and Mass Transfer, Vol. 88, pp. 902-913.

Das, S.K., Putra, N. and Roetzel, W. (2003), "Pool boiling characteristics of nano-fluids", International Journal of Heat and Mass Transfer, Vol. 46 No. 5, pp. 851-862.

de Vahl Davis, G. (1983), "Natural convection of air in a square cavity: a benchmark numerical solution", International Journal for Numerical Methods in Fluids, Vol. 3 No. 3, pp. 249-264.

Einstein, A. (1905), "Über die von der molekularkinetischen theorie der wärme geforderte bewegung von in ruhenden flüssigkeiten suspendierten teilchen", Annalen Der Physik, (in German), Vol. 17, pp. 549-560.

Garoosi, F. and Hoseininejad, F. (2016), "Numerical study of natural and mixed convection heat transfer between differentially heated cylinders in an adiabatic enclosure filled with nanofluid", Journal of Molecular Liquids, Vol. 215, pp. 1-17.

Garoosi, F. and Talebi, F. (2017a), "Numerical simulation of conjugate conduction and natural convection heat transfer of nanofluid inside a square enclosure containing a conductive partition 
and several disconnected conducting solid blocks using a buongiorno's two phase model", 30,6 Powder Technology, Vol. 317, pp. 48-71.

Garoosi, F. and Talebi, F. (2017b), "Numericalanalysis of conjugate natural and mixed convection heat transfer of nanofluids in a square cavity using the two-phase model", Advanced Powder Technology, Vol. 28 No. 7, pp. 1668-1695.

Garoosi, F., Bagheri, G. and Rashidi, M.M. (2015a), "Two phase simulation of natural convection and mixed convection of the nanofluid in a square cavity", Powder Technology, Vol. 275, pp. 239-256.

Garoosi, F., Bagheri, G. and Talebi, F. (2013), "Numerical simulation of natural convection of nanofluids in a square cavity with several pairs of heaters and coolers (HACs) inside", International Journal of Heat and Mass Transfer, Vol. 67, pp. 362-376.

Garoosi, F., Hoseininejad, F. and Rashidi, M.M. (2016a), "Numerical study of heat transfer in a heat transfer performance of nanofluids in a heat exchanger", Applied Thermal Engineering, Vol. 105, pp. $436-455$.

Garoosi, F., Hoseininejad, F. and Rashidi, M.M. (2016b), "Numerical study of natural convection heat transfer in a heat exchanger filled with nanofluids", Energy, Vol. 109, pp. 664-678.

Garoosi, F., Jahanshaloo, L., Rashidi, M.M. and Badakhsh, A. (2015b), "Numerical simulation of natural convection of the nanofluid in heat exchangers usiang a buongiorno model", Applied Mathematics and Computation, Vol. 254, pp. 183-203.

Giddings, J.C., Shinudu, P.M. and Semenov, S.N. (1995), "Thermophoresis of metal particles in a liquid”, Journal of Colloid Interface Science, Vol. 176 No. 2, pp. 454-458.

Gobin, D. and Bennacer, R. (1996), "Cooperating thermosolutal convection in encloseres-II. Heat transfer and flow structure", International Journal of Heat and Mass Transfer, Vol. 39 No. 13, pp. 2683-2697.

He, Y., Jin, Y., Chen, H., Ding, Y., Cang, D. and Lu, H. (2007), "Heat transfer and flow behaviour of aqueous suspensions of $\mathrm{TiO}_{2}$ nanoparticles (nanofluids) flowing upward through a vertical pipe", International Journal of Heat and Mass Transfer, Vol. 50 Nos 11/12, pp. 2272-2281.

Hortmann, M., Peric, M. and Scheuerer, G. (1990), "Finite volume multigrid prediction of laminar natural convection: bench-mark solutions", International Journal for Numerical Methods in Fluids, Vol. 11 No. 2, pp. 189-207.

Hu, Y., He, Y., Qi, C., Jiang, B. and Schlaberg, H.I. (2014), "Experimental and numerical study of natural convection oin a square enclosure filled with nanofluid", International Journal of Heat and Mass Transfer, Vol. 78, pp. 380-392.

Incropera, F.P., Dewitt, D.P., Bergman, T.L. and Lavine, A.S. (2007), Fundamentals of Heat and Mass Transfer, 6th ed., John Wiley and Sons, Hoboken, NJ.

Keblinski, P., Phillpot, S.R., Choi, S.U.S. and Eastman, J.A. (2002), "Mechanisms of heat flow in suspensions of nano-sized particles (nanofluids)", International Journal of Heat and Mass Transfer, Vol. 45 No. 4, pp. 855-863.

Khalili, E., Saboonchi, A. and Saghafian, M. (2017), "Natural convection of $\mathrm{Al}_{2} \mathrm{O}_{3}$ nanofluid between two horizontal cylinders inside a circular enclosure”, Heat Transfer Engineering, Vol. 38 No. 2, pp. 177-189.

Leonard, B.P. (1979), "A stable and accurate convective modelling procedure based on quadratic upstream interpolation”, Computational Methods of Applied Mechanical Engineering, Vol. 19 No. 1, pp. 59-78.

McNab, G.S. and Meisen, A. (1973), "Thermophoresis in liquids”, Journal of Colloid Interface Science, Vol. 44 No. 2, pp. 339-346.

Mahdi, H.S. and Kinney, R.B. (1990), "Time-dependent natural convection in a square cavity: application of a new finite volume method", International Journal for Numerical Methods in Fluids, Vol. 11 No. 1, pp. 57-86. 
Noghrehabadi, A., Samimi Behbahan, A. and Pop, I. (2015), "Thermophoresis and brownian effects on natural convection of nanofluids in a square enclosure with two pairs of heat source/sink", International Joumal of Numerical Methods for Heat and Fluid Flow, Vol. 25 No. 5, pp. 1030-1046.

Pak, B.C. and Cho, Y.I. (1998), "Hydrodynamic and heat transfer study of dispersed fluids with submicron metallic oxide particles", Experimental Heat Transfer, Vol. 11 No. 2, pp. 151-170.

Patankar, S.V. (1980), Numerical Heat Transfer and Fluid Flow, Hemisphere Publishing, Washington, DC.

Patankar, S.V. and Spalding, D.B. (1972), "A calculation procedure for heat, mass and momentum transfer in three-dimensional parabolic flows", International Journal of Heat and Mass Transfer,

Buoyancyinduced convection Vol. 15 No. 10, pp. 1787-1797.

Prasher, R., Song, D., Wang, J. and Phelan, P. (2006), "Measurements of nanofluid viscosity and its implications for thermal applications", Applied Physics Letters, Vol. 89 No. 13, pp. 133108.

Putra, N., Roetzel, W. and Das, S.K. (2003), "Natural convection of nano-fluids", Heat Mass Transfer, Vol. 39 Nos 8/9, pp. 775-784.

Rauch, J., Hartung, M., Privalov, A.F. and Köhler, W. (2007), "Correlation between thermal diffusion and solvent self-diffusion in semidilute and concentrated polymer solutions", Journal of Chemical Physics, Vol. 126 No. 21, p. 214901.

Sheremet, M. and Chinnasamy, S. (2018), "Convective-radiative heat transfer in a cavity filled with a nanofluid under the effect of a nonuniformly heated plate", International Journal of Numerical Methods for Heat and Fluid Flow, Vol. 28 No. 6, pp. 1392-1409.

Van Doormaal, J.P. and Raithby, G.D. (1984), "Enhancements of the simple method for predicting incompressible fluid flows", Numerical Heat Transfer, Vol. 11, pp. 147-163.

Wan, D.C., Patnail, B.S.V. and Wei, G.W. (2001), "A new benchmark quality solution for the buoyancydriven cavity by discrete singular onvolution”, Numerical Heat Transfer, Vol. 40, pp. 199-228.

Zhang, K.J., Briggs, M.E., Gammon, R.W., Sengers, J.V. and Douglas, J.F. (1999), "Thermal and mass diffusion in a semidilute good solvent-polymer solution", Journal of Chemical Physics, Vol. 111 No. 5, pp. 2270-2282.

Zhou, S.Q. and Ni, R. (2008), "Measurement of the specific heat capacity of water-based $\mathrm{Al}_{2} \mathrm{O}_{3}$ nanofluid", Applied Physics Letters, Vol. 92 No. 9, p. 93123.

\section{Corresponding author}

Massimo Corcione can be contacted at: massimo.corcione@uniroma1.it

For instructions on how to order reprints of this article, please visit our website:

www.emeraldgrouppublishing.com/licensing/reprints.htm

Or contact us for further details: permissions@emeraldinsight.com 